\title{
Impact of Motivational Factors on the Work Results of Lecturers at Vietnam National University, Hanoi*
}

\author{
Anh Duc DO ${ }^{1}$, Ngoc Thach PHAM ${ }^{2}$, Hong Phuong BUI ${ }^{3}$, Duc Thanh VU ${ }^{4}$, \\ The Kien NGUYEN 5 , Thi Huyen NGUYEN ${ }^{6}$
}

Received: June 05, 2020 Revised: June 14, 2020 Accepted: July 09, 2020

\begin{abstract}
This paper aims to develop a conceptual framework for evaluating the impact of motivational factors on the work results of lecturers at Vietnam National University, Hanoi (VNU), one of two leading multidisciplinary and multi-sectoral national universities in Vietnam. This study has considered wages and other benefits (WB), training and development (TD), working environment (WE) and working motivation (WM) as motivational factors, and proposed a structural model of the impact of motivational factors on the work results of lecturers at VNU. The empirical analysis used data from the survey data of 321 university lecturers. Comprehensive, valid, and reliable tools (SPSS 26 and SmartPLS 3.0 software) are used to evaluate rigorous statistical tests including convergence validity, discriminatory validity, reliability, and average variance extracted to analyze and verify the gathered data, and the hypotheses developed. The result of path analysis shows that four motivational factors constitute a structured system with different degrees of influence on the work results of lecturers. There is also a positive relationship between the motivational factors and the work results of lecturers. As a result, it can be concluded that all hypotheses developed are supported. Several recommendations are further suggested to improve the performance of lecturers at VNU.
\end{abstract}

Keywords: PLS SEM, Motivational Factors, Lecturers’ Work Result, Vietnam National University, Hanoi

JEL Classification Code: C30, A20, I20, J81

\section{Introduction}

\section{*Acknowledgements:}

This research is funded by Vietnam National Foundation for Science and Technology Development (NAFOSTED) under grant number 503.01-2018.03.

${ }^{1}$ First Author and Corresponding Author. Lecturer, School of Trade and International Economics, National Economics University, Vietnam [Postal Address: 207 Giai Phong Road, Dong Tam Ward, Hai Ba Trung District, Hanoi, 113068, Vietnam] Email:ducda@neu.edu.vn

${ }^{2}$ Chairman, Board of Trustees, Hanoi University, Vietnam.

Email: thachpn@hanu.edu.vn

${ }^{3} \mathrm{PhD}$ Candidate, VNU University of Economics and Business, Vietnam National University, Vietnam. Email: phuongbh@vnu.edu.vn

${ }^{4}$ Associate Professor, Lecturer, VNU University of Economics and Business, Vietnam. Email: thanhvd@vnu.edu.vn

${ }^{5}$ Lecturer, VNU University of Economics and Business, Vietnam National University, Vietnam. Email: nguyenthekien@vnu.edu.vn

${ }^{6}$ Officier, VNU University of Economics and Business, Vietnam National University, Vietnam. Email: nthuyen.ueb@vnu.edu.vn

(c) Copyright: The Author(s)

This is an Open Access article distributed under the terms of the Creative Commons Attribution Non-Commercial License (http://Creativecommons.org/licenses/by-nc/4.0/) which permits unrestricted noncommercial use, distribution, and reproduction in any medium, provided the original work is properly cited.
Motivation is one of the critical tools to encourage employees to achieve outstanding results (Njotoprajitno et al., 2020). Motivated employees can lead to increase productivity and allow organizations to achieve higher levels of output. Motivation in the work place has become a very popular topic, since 1970s and early 1980s (Ambrose \& Kulik, 1999). Many researchers have expressed their view on the concept of motivation. Motivation can be defined as a driving force that compels an individual to take actions with a goal to achieve certain goals (Maslow, 1943; Shahzadi et al., 2014) or an attempt to achieve a goal (Bedeian, 1993). According to Kleinginna Jr and Kleinginna (1981), motivation is a push from within individuals to meet their unsatisfied needs. This implies, motivation is a force that drives people to do things that they would not normally do. In a workplace, motivation embraces all factors in an employee's development toward the achievement of organizational goals. Robins and Coulter (2005) stated that motivation as "willingness to exert high level of inspiration to reach organizational goals, conditioned by the efforts ability to satisfy some individual need". On the other hand, 
motivation is about giving your staff the right mixture of guidance, direction, resources and rewards, so that they are inspired and keen to work on the way that you want them to (Nabi et al., 2017; Griffin, 2013).

In higher education, motivation plays an important role in educational institutions to enhance lecturers' performance and efficiency (Akhtar \& Iqbal, 2017). Mertler (1992) pointed out that if lecturers are satisfied, performance can be improved and can affect students' achievement (Le, 2020). A considerable amount of literature has been published on determinants of lecturer motivation. These include recognition of individual contributions (Situma, 2015), wages and other benefits (Wright, 1985; Ai et al., 2019), working environment (Situma, 2015; Rasheed et al., 2016; Ai et al., 2019), advancement opportunities (Ai et al., 2019), working motivation, performance management system (Rasheed et al., 2016; Rasheed et al., 2010), training and development (Rasheed et al., 2016). However, few of them have examined the impact of universities' motivational factors on lecturers' performance (Hairuddin et al., 2017; Ai et al., 2019).

Vietnam National University, Hanoi (VNU) is one of two leading multidisciplinary and multi-sectoral national universities in Vietnam, tasked with producing highly qualified human resources for the development of the country. In recent years, VNU has encouraged innovation in training and research to keep pace with other top universities around the world and continued to expand its training to include new disciplines in line with development trends and human resource requirements of national and multinational corporations and enterprises. In doing so, it produces high quality human resources, fosters talent, performs key research tasks in the fundamental sciences and technology, and leads Vietnam's social-economy. Consequently, VNU has had many activities and solutions to motivate and improve the effectiveness of lecturers. Therefore, the purpose of this study is to evaluate the impact of motivational factors on the work results of lecturers at VNU. We develop a conceptual framework for evaluating the impact of motivational factors on the work results of lecturers at VNU. Through an empirical investigation using the PLS-SEM methods, this research contributes to understanding how the influential factors of motivational factor affect the work result at VNU.

The paper is divided into five sections. In section 2, an overview of research on motivation and work results of lecturer are provided and a structural model for the the impact of motivational factors on the work results of lecturers are proposed. In Section 3, the methodology of the study is considered in greater detail in order to explains how we used it in this study. In section 4, the analysis results in the case of Vietnam National University are presented. Finally, in section 5, certain conclusions are drawn, and several recommendations are further suggested improving the performance of lecturers.

\section{Literature Review}

In recent years, there has been an increasing interest in lecturers' motivation and performance. Many studies had also been conducted to identify factors that motivate lecturers, but their findings are slightly different depending on the study population (Gautreau 2011; Schifter, 2000). Motivation usually comes from two sources: internal factors and external factors (Reeve, 2001). Employees' motivation is often affected by both the factors simultaneously (Rasheeh, 2016). Internal factors include the ability of the lecturer, individual contributions, working motivation, promotion opportunities, workplace relationships and recognition (Sebaluck \& Seegum, 2013; Situma, 2015). External factors include school policy, working environment, training and development, wages and other benefits (Sebaluck \& Seegum, 2013; Situma, 2015; Rasheed et al., 2016; Do et al., 2019; Do et al., 2020; Do \& Canh, 2018; Ai et al., 2019). These factors have a positive effect on job satisfaction, and the lack of these factors will lead to a decrease in job satisfaction among lecturers (Lee \& Kim, 2019). Tella et al. (2007) suggested that bonuses are seen as a motivational strategy to improve work productivity, commitment to work, and lecturers' satisfaction. Shah et al. (2012) indicated that motivation of lecturers were effected by bonuses, recognition, satisfaction with leadership and job characteristics. Seebaluck and Seegum (2013) analyzed the factors influencing teachers' motivation at a public elementary school in Mauritius. Their results showed that seven factors strongly influence the motivation of teachers include: (1) sense of accomplishment; (2) ability to communicate and impart knowledge to students; (3) the fulfillment of desires in one's profession; (4) develop social relationships; (5) responsibility for teaching; (6) opportunities to improve career skills and (7) social status.

The results of lecturers' work are evaluated mainly in two aspects: teaching and scientific research. In order to evaluate faculty, Costa and Oliveira (2012) used four main criteria and sub-criteria including teaching (pedagogical publications, student supervision, course teaching), research (scientific publications, scientific projects), knowledge transfer (patents, legislation, norms and technical publications; service, consultancy and dissemination of science and technology), and university management. Chen et al. (2015) used many criteria and sub-criteria to evaluate teaching performance including planning and preparation, communication and interaction, teaching for learning, managing the learning environment, student evaluation and professionalism. Karmaker et al. (2018) applied an integrated analytic hierarchy process (AHP) and Technique for Order preference by Similarity to Ideal Solution 
(TOPSIS) model to evaluate lecturers' performance of a renowned engineering university of Bangladesh. Fifteen subcriteria of five main performance evaluation indicators were considered including subject knowledge (ability of teaching, understand student psychology, problem solving capability), ability of commutation (clear idea, accessibility, power of explanation), discipline (fair, attitude, well-organized), cooperative (good guidance, dedicated, power of motivation), creative (positive reinforcement, passionate, inspirational).

Duc et al. (2019) developed a technique to support the process of evaluating lecturer's performance through use of a new Dynamic Fuzzy Order Preference by Similarity to Ideal Solution (DFTOSIC). Tauhed et al. (2019) indicated that journal article, book and research funding are importance criteria to evaluate lecturers' research performance. Dat at al. (2019) applied a multi-criteria decision making to assess lecturer' performance at Vietnam National University, Hanoi based on sets of criteria and decision making committee. The results showed that the proposed method is feasible to solve the real life problem and an extension of the existing approaches. Duc et al. (2020) applied the TOPSIS method in an interval-valued complex neutrosophic set environment to evaluate lecturers" performance. Four criteria with 13 sub-criteria were used in their approach including selfevaluation, manager-based evaluation, peer-evaluation and student-based evaluation.

Several studies have considered the impacts of motivation to work on the performance of lecturers (e.g., Do et al., 2019; Do et al., 2020; Huynh, Do, \& Truong, 2019; Le, 2020; Lee \& Kim, 2019; Luu, Do, Canh, Nguyen, \& Thai, 2019). Davidson (2007) found out the influence of organizational culture factors on the performance of teachers. Only by creating an appropriate culture in the organization, will the staff feel comfortable in communicating with colleagues and superiors, thereby making the job more effective. Nadeem et al. (2014) indicated that lecturers' performance was influenced by social and economic conditions. Negussie (2014) explored the five core needs in Maslow's theory of demand pyramid how they affect teachers' work. Teacher motivation will be reduced when working conditions are not well met, thereby reducing work efficiency. Shahzadi et al. (2014) evaluated the impact of employees' motivation on work results, indicating that there is a positive relationship between work motivation and employee performance. They also indicated that internal factors such as salary and bonuses will had a positive impact on employee productivity and work efficiency.

Rasheed et al. (2016) found out that although compensation packages and financial incentives are important factors for employees in the competitive market environment of the higher education sector but some other factors like job design and working environment, performance management system, and training and development are also significant. Hairuddin et al. (2017) analyzed the influence of motivation, competence and organizational commitment to job satisfaction and performance of lecturers. Their results indicated that motivation has a positive and significant effect on lecturers' job satisfaction and lecturers' performance. Competence has a positive and insignificant effect on lecturers' job satisfaction, but significant on lecturers performance. Organizational commitment has a positive and significant effect on lecturers' job satisfaction and lecturers' performance. Ai et al. (2019) applied structural equation modeling to analyze the factors affecting work motivation of non-public university lecturers in Ho Chi Minh City. They found that while six factors positively affect the work motivation of lecturers including advancement opportunities, organizational culture, recognition of individual contribution, lecturer's qualifications, wages and other benefits, and working environment. Two other factors, i.e., the characteristics of teaching and learning and the class size have been found to be not statistically significant.

From the literature, and invoking the contingency theory perspective, this study suggested that the motivational factors of lecturers include wages and other benefits (WB), training and development (TD), working environment (WE) and working motivation (WM), and proposed a structural model of the impact of motivational factors on the work results of lecturers at VNU. Consequently, there is a need for an in-depth and systematic investigation of these factors taken together to study how they interact with each other, and how they affect the work results of leturers. Further, based on the above statements of motivational factors and the working result of lecturers, this study is going to test four hypotheses as follows:

$\boldsymbol{H}_{1}:$ Wages and other benefits have a positive effect on lecturers' work results

$\boldsymbol{H}_{2}:$ Training and development have a positive effect on lecturers' work results

$\boldsymbol{H}_{3}$ : Working environment has a positive effect on lecturers'work results work

$\boldsymbol{H}_{4}$ : Working motivation has a positive effect on lecturers'

\section{Research Methodology}

\subsection{Research Sample}

Based on the literature review, this study examines the impact of four motivational factors (scales) to lecturers' work results (LR) in Figure 1, including: wages and other benefits (WB), training and development (TD), working environment (WE) and working motivation (WM). The questionnaires were distributed firstly to 15 experts to check how they understand the questions. Afterward, we revised 
the final questionnaire form based on the suggestions from respondents in two seminars and use it for collecting data. In the final questionnaire, the factor WB is measured by six observed variables (WB.1-WB.6), the factor TD is measured by seven observations (TD.1 - TD.7), the factor WE is measured by six observed variables (WE1 - WE.6), the factor WM is measured by six observations (WM.1 WM.6), and the lecturers' work results is measured by seven observed variables (LR.1 - LR.7) (see Figure 1).

The completed questionnaire was sent to lecturers who are working at VNU. The number of valid questionnaires received is 321. According to Hair et al. (2016), the minimum sample size should be 10 times the maximum number of arrowheads pointing at a latent variable anywhere in the PLS path model. We collected 1050 samples of survey questions from different lecturers at VNU by units, including University of Social Sciences and Humanities (USSH), University of Science (US), University of Engineering and Technology (UET), University of Languages and International Studies (ULIS), University of Economics and Business (UEB), University of Education (UED),
Vietnam-Japan University (VJU), School of Law (SoL), International School (IS), School of Medicine and Pharmacy (SMP), School of Interdisciplinary Studies (SIS), and Hanoi School of Business and Management (HSB). Lecturer's motivational factors and work results aspects were measured using questionnaire based on Likert scales (which is common within an SEM context) divided into five levels: (1) strongly disagree, (2) disagree, (3) neither agree nor disagree, (4) agree, and (5) strongly agree. There are 321 were valid for analysis which represents $31 \%$. Table 1 shows the profile of studied respondents.

Based on gender, there were more female lecturers than male lecturers, with 163 female lecturers (49.2\%) and 158 male lecturers (49.2\%). From educational background, the most respondents were those who had Ph.D degree qualification. So, 264 respondents $(82.2 \%)$ were lecturers who have Ph.D degree, 38 respondents $(11.8 \%)$ were lecturers who have Master degree, and 19 respondents (5.9\%) were Associate Professor/Professor. The respondents of this study had various teaching experiences, in which 109 $(34.0 \%)$ of them had of five-to-ten years teaching experience,

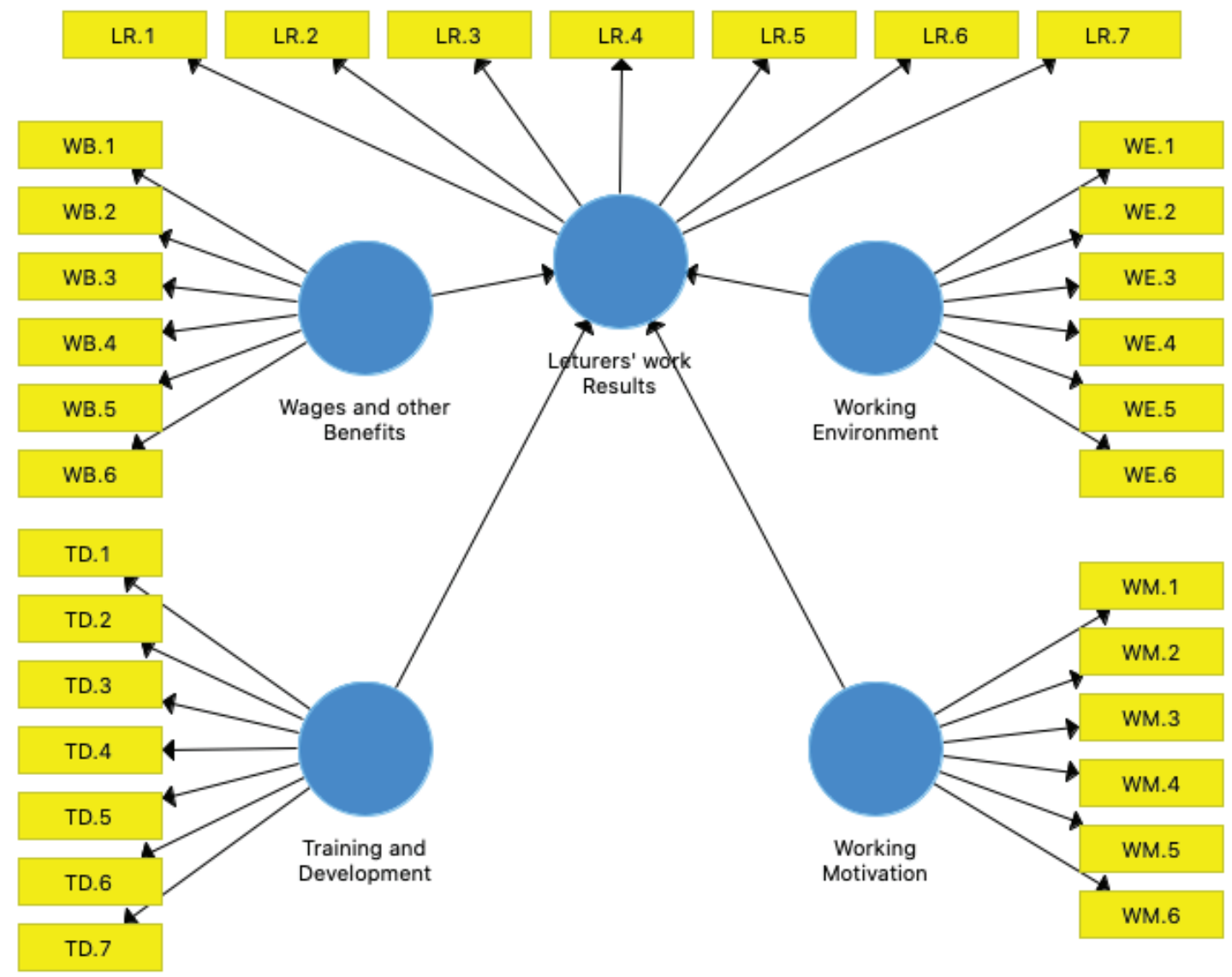

Figure 1: The structural model 
Table 1: The Profile of Studied Respondents.

\begin{tabular}{|l|l|c|c|}
\hline & & Frequency & Percent (\%) \\
\hline \multirow{3}{*}{ Gender } & Male & 158 & 50.8 \\
\cline { 2 - 4 } & Female & 163 & 49.2 \\
\hline \multirow{5}{*}{ Teaching experience } & $<5$ years & 152 & 47.4 \\
\cline { 2 - 4 } & $5-10$ years & 109 & 34.0 \\
\cline { 2 - 4 } & $>10$ years & 60 & 18.7 \\
\hline \multirow{3}{*}{ Degree } & Master & 38 & 11.8 \\
\cline { 2 - 4 } & Ph. D & 264 & 82.2 \\
\cline { 2 - 4 } & Associate Professor/Professor & 19 & 5.9 \\
\hline \multirow{2}{*}{ Total } & & 321 & 100 \\
\hline
\end{tabular}

$152(47.4 \%)$ respondents had less than five years of teaching experience, and $60(18.7 \%)$ respondents had more than ten years teaching experience.

\subsection{Data Analysis Techniques}

Our research has provided an empirical evidence for evaluating the impact of motivational factors on the work results of lecturers at Vietnam National University, Hanoi. After collecting result of survey questionnaires, the data were encrypted, cleaned, and then imported into SPSS 26 for reliability analysis and EFA discovery factor analysis. This study utilizes the Cronbach's Alpha (CA) analysis as the reliability test after all respondents' answers of observed variables are valid. This analysis is conducted by comparing the CA value with 0.7. A collection of convincing observed variables are reliable if the CA is higher than 0.7 (Ghozali, 2016). Then, EFA was used to check convergent and discriminant values of the variables. EFA must satisfy the following requirements: factor loading is over $0.5, \mathrm{KMO} \leq$ $0.5 \leq 1$, Bartlett test the statistical significance (Sig. $<0.05$ ), percentage of variance in Extraction Sums of Squared Loadings are over $50 \%$. Finally, we used a comprehensive, valid, and reliable tool (SmartPLS 3.0 software) to evaluate rigorous statistical tests including convergence validity, discriminatory validity, reliability, and average variance extracted (AVE) to analyze and verify the gathered data, and the hypotheses developed.

\section{Empirical Results}

\subsection{Testing the Reliability of the Scales}

This study uses the Cronbach's Alpha (CA) analysis to determine the reliability of the valid variables for the scales (including wages and other benefits, training and development, working environment and working motivation) as well as lecturers' work results. All scales showed Cronbach's Alpha reliability levels are higher than 0.7 and the values of Corrected Item-Total Correlation are higher than 0.4 are acceptable, the reliability test stand reached.

\subsection{Exploratory Factor Analysis}

After analyzing Cronbach's Alpha, four factors (independent variables) with 24 observed variables were included for Exploratory Factor Analysis (EFA). KMO test coefficient calculated from the sample is $0.895<1.0$. Thus, the sample size of the survey is eligible to conduct EFA. Bartlett's Test of Sphericity value is significant with $P_{-}$value $=0,00$. This value indicates that the observed variables are correlated with respect to the total number of observations. The result of total variance explained indicates that 04 factors explain $56.664 \%$ is larger than $50 \%$ of the variation of the data set.

\subsection{Structural Model}

In the structural model, regression paths were specified from the basic need latent variables directly to the four motivational factors variables (wages and other benefits, training and development, working environment, and working motivation), which in turn predicted the work results of lecturers variables.

\subsubsection{Reliability and Validity of Model}

The results in Table 2, showed that all the composite reliabilities for our constructs were above 0.7 and each construct's variance extracted was above the recommended value of 0.5 (Hair et al., 2016). As a result, we have concluded that all our constructs had satisfactory convergent validity. 
Table 2: Construct Reliability and Validity.

\begin{tabular}{|l|c|c|c|c|}
\hline & Cronbach's Alpha & rho_A & Composite Reliability & Average Variance Extracted (AVE) \\
\hline Leturers' work Results & 0.883 & 0.885 & 0.912 & 0.634 \\
\hline Training and Development & 0.824 & 0.825 & 0.877 & 0.589 \\
\hline Wages and other Benefits & 0.840 & 0.841 & 0.886 & 0.609 \\
\hline Working Environment & 0.820 & 0.822 & 0.874 & 0.581 \\
\hline Working Motivation & 0.858 & 0.864 & 0.898 & 0.639 \\
\hline
\end{tabular}

Table 3: Discriminant validity (Fornell-Larcker Criterion)

\begin{tabular}{|l|c|c|c|c|c|}
\hline & $\begin{array}{c}\text { Leturers' } \\
\text { work Results }\end{array}$ & $\begin{array}{c}\text { Training and } \\
\text { Development }\end{array}$ & $\begin{array}{c}\text { Wages and } \\
\text { other Benefits }\end{array}$ & $\begin{array}{c}\text { Working } \\
\text { Environment }\end{array}$ & $\begin{array}{c}\text { Working } \\
\text { Motivation }\end{array}$ \\
\hline Leturers' work Results & 0.796 & & & & \\
\hline Training and Development & 0.692 & 0.767 & & & \\
\hline Wages and other Benefits & 0.480 & 0.390 & 0.780 & & \\
\hline Working Environment & 0.474 & 0.411 & 0.211 & 0.762 & \\
\hline Working Motivation & 0.670 & 0.542 & 0.372 & 0.511 & 0.799 \\
\hline
\end{tabular}

Table 4: Hypothesis result.

\begin{tabular}{|l|c|c|c|c|c|}
\hline & $\begin{array}{c}\text { Original } \\
\text { Sample (O) }\end{array}$ & $\begin{array}{c}\text { Sample } \\
\text { Mean (M) }\end{array}$ & $\begin{array}{c}\text { Standard Deviation } \\
\text { (STDEV) }\end{array}$ & $\begin{array}{c}\text { T Statistics } \\
\text { (|O/STDEV|) }\end{array}$ & P Values \\
\hline $\begin{array}{l}\text { Training and Development -> } \\
\text { Leturers' work Results }\end{array}$ & 0.399 & 0.398 & 0.050 & 8.019 & 0.000 \\
\hline $\begin{array}{l}\text { Wages and other Benefits -> } \\
\text { Leturers' work Results }\end{array}$ & 0.178 & 0.177 & 0.042 & 4.213 & 0.000 \\
\hline $\begin{array}{l}\text { Working Environment -> } \\
\text { Leturers' work Results }\end{array}$ & 0.101 & 0.102 & 0.044 & 2.288 & 0.022 \\
\hline $\begin{array}{l}\text { Working Motivation -> } \\
\text { Leturers' work Results }\end{array}$ & 0.336 & 0.338 & 0.054 & 6.192 & 0.000 \\
\hline
\end{tabular}

For testing the discriminant validity, we used two tests for discriminant validity: comparison of item loadings with item cross loadings and comparison of the variance extracted from the construct with shared variance. According to Henseler et al. (2015), the top coefficients that are larger than the correlation coefficients in the same column (FornellLarcker matrix coefficient) have satisfied the condition as suggested. Table 3 shows that all items were satisfied the condition of discriminant validity.

\subsubsection{PLS Structural Model Results}

We next examined the overall explanatory power of the structural model, the variance explained by the independent variables, and the magnitude and strength of its paths, where each of our hypotheses corresponds to a specific structural model path. According to Henseler et al., (2015), we conduct the test with sample size Bootstrapping $\mathrm{N}=5000$ (Henseler et al., 2015). With P_value $<1 \%, 5 \%$, and $10 \%$, the proposed hypotheses are considered as statistically significant at the $99 \%, 95 \%$ and $90 \%$ reliability levels. The result in Table 4 is as follows:

Result from Table 4 and Figure 2 indicates that three hypotheses in our conceptual model are fully supported and one hypothesis is supported. $\mathrm{H}_{1}$ estimations for the relationships of the among wages and other benefits with lecturers' work results, $\mathrm{H}_{2}$ estimations for the relationships of the among training and development with lecturers' work results, and $\mathrm{H}_{4}$ estimations for the relationships of the among working motivation with lecturers' work results are fully supported $\left(P_{-} \_\right.$value $\left.=0.000\right)$. This results also show that wages and other benefits, training and development, 


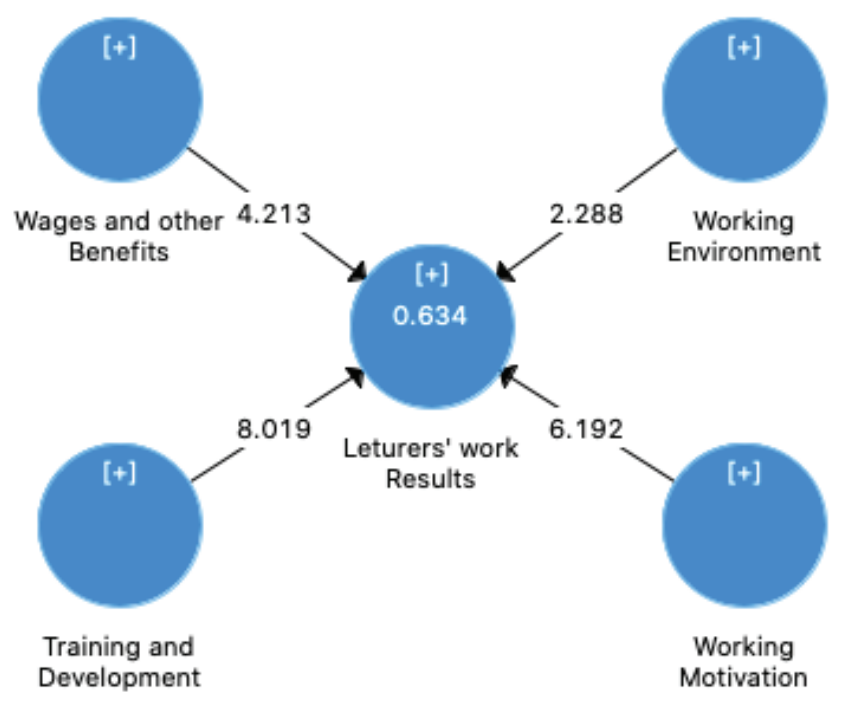

Figure 2: Research model result

and working motivation have a positive relationship with lecturers' work results. The prediction of relationship between working environment and lecturers' work results is supported $\left(\mathrm{P}_{-}\right.$value $\left.<0.05\right)$. The results of $\mathrm{H}_{3}$ also shows the positive relationship between working environment and lecturers' work results. As a result, the testing of the relationship between the motivational factors and work results of lecturers at Vietnam National University, Hanoi has been verified and supported.

\section{Conclusion and Recommendations}

The major purpose of this study was to examine and analyze the impact of wages and other benefits, training and development, working environment, and working motivation on lecturers' work results at Vietnam National University, Hanoi. The data were analyzed using comprehensive, valid, and reliable tools (SPSS 26 and SmartPLS 3.0 software) to evaluate rigorous statistical tests including convergence validity, discriminatory validity, reliability, and average variance extracted to analyze and verify the gathered data, and the hypotheses developed. Specifically, this study was conducted to find out which motivational factor has the greatest influence on the lecturers' work results at Vietnam National University, Hanoi.

Among these variables, training and development (TD) is the most effective factor $(\beta=0.399)$. According to Rasheed et al. (2016), lecturers' training and development are very important to enhance their knowledge, skills and to give them confidence to compete in the industry. Therefore, in order to improve the lecturers' work results, VNU-affiliated universities need to promote short-term training programs, as well as create favorable conditions for lecturers to exchange research and teaching at foreign countries. Working motivation (WM) with $\beta=0.336$ have the second strongest influence on lecturers' work results at VNU. This implies that when lecturers are well encouraged, this impacts their performance. This finding is supported by Ai et al. (2019) and Narasuci et al. (2018). Working environment (WE), wages and other benefits (WB) are also two significant factors that affect the lecturers' work results at VNU. These factors can encourage the increase in the work results of lecturers while working. These factors indicate that lecturers are not really satisfied with the current salary and working environment. The impact of these factors on lecturers' work results need to be understood by VNUaffiliated universities' management to improve the lecturers' work results. These results are supported by several previous studies. Narasuci et al. (2018) also found there is a positive and significant effect of the work environment on lecturer performance and work motivation, work motivation. Ai et al. (2019) indicated that wages and other benefits and working environment has positively affected the work motivation of lecturers.

This study is an attempt to understand how wages and other benefits, training and development, working environment, and working motivation affect lecturers' work results at VNU. Based on the discussion of findings about the impact of motivational factors on the work results of lecturers at Vietnam National University, Hanoi (VNU), although it was at the satisfactory level, it needs to be improved in the future by holding various activities to improve lecturers' motivation and it must be done consistently to guarantee lecturer's educational quality in line with more challenging education in the digital era.

For future research, we propose some recommendations. Firstly, the sample only covered 321 lecturers at Vietnam National University, Hanoi, so it may not represent all lecturers in Vietnam. Future studies with larger samples could be conducted to allow for comparisons among lecturers in Vietnam. Secondly, this study only emphasized on constructs related between motivational factors and work results of lecturers. Other constructs that should be studied to measure the lecturer's performance are professional competencies, incentives, work ethics, facilitators, etc.

\section{References}

Ai, T. H., My, T. P. T., \& Chieu, M. P. T. (2019). Work motivation of lecturers in non-public universities: the case of Ho Chi Minh city, Vietnam. The EUrASEANs: Journal on Global SocioEconomic Dynamics, 4(17), 46-58.

Akhtar, J. H., \& Iqbal, I. (2017). Impact of Motivation on Teachers' Job Performance: A Case Study of a Public Sector University. Journal of Educational Sciences and Research, 4, 53-71. 
Ambrose, M. L., \& Kulik, C. T. (1999). Old friends, new faces: Motivation research in the 1990s. Journal of Management, 25(3), 231-292.

Bedeian, A.G. (1993). Management (3rd ed.). New York, NY: Press Dryden.

Chen, J. F., Shieha, H. N., \& Hung, D. Q. (2015). Evaluating teaching performance based on fuzzy AHP and comprehensive evaluation approach. Applied Soft Computing, 28, 100-108.

Costa, C. A. B., \& Oliveira, M. D. (2012). A multicriteria decision analysis model for faculty evaluation, Omega, 40(4), 424-436. https://doi.org/10.1016/j.omega.2011.08.006

Davidson (2007). The Pivotal Role of Teacher Motivation in Tanzanian Education. The Educational Forum, Winter, 157166.

Do, A. D, \& Canh, C. C. (2018). Designing Standards for Lecturers at Research Based Universities in Vietnam. Journal of Economics and Development, 252(2), 20-32.

Do, A. D., Pham, M. T., Dinh, T. H, Ngo, T. C, Luu, Q. D, Pham, N. T, Ha, D. L., \& Vuong, H. N. (2020). Evaluation of lecturers' performance using a novel hierarchical multi-criteria model based on an interval complex Neutrosophic set. Decision Science Letters, 9, 119-144.

Do, D. A., Pham, N. T., Bui, H. P., Canh, C. D., Luu, H. V., \& Pham, T. H. D. (2019). A dynamic fuzzy multiple criteria decisionmaking approach for lecturer performance evaluation. Journal of Management Information and Decision Sciences, 22(3), 250-261

Gautreau, C. (2011). Motivational Factors Affecting the Integration of a Learning Management System by Faculty. Journal of Educators Online, 8(1), 1-25.

Griffin, R. W. (2013). Management (11 $1^{\text {th }}$ ed.). Boston, MA: South Western Cengage Learning.

Hair Jr, J. F., Sarstedt, M., Matthews, L. M., \& Ringle, C. M. (2016). Identifying and treating unobserved heterogeneity with FIMIX-PLS: Part I-method. European Business Review, 28(1), 63-76. https://doi.org/10.1108/EBR-09-2015-0094

Hairuddin, A., Gani, M. U., Sinring, B., \& Arifin, Z. (2017). Motivation, Competence and Organizational Commitment. IRA-International Journal of Management and Social Sciences, 6(3), 419-428.

Henseler, J., Ringle, C. M., \& Sarstedt, M. (2015). A new criterion for assessing discriminant validity in variance-based structural equation modeling. Journal of the Academy of Marketing Science, 43(1), 115-135.

Huynh, T. T. S., Do, D.T., \& Truong T. X. D. (2019). The Impact of Leadership Styles on the Engagement of Cadres, Lecturers and Staff at Public Universities - Evidence from Vietnam. Journal of Asian Finance, Economics and Business, 6(1), 273-280. http://doi.org/10.13106/jafeb.2019.vol6.no1.273

Karmaker, C. L., Ahmed, S. M. T., Rahman, M. S., Tahiduzzaman, M., Biswas, T. K., Rahman, M., \& Biswas, S. K. (2018). A framework of faculty performance evaluation: A case study in
Bangladesh. International Journal of Research in Advanced Engineering and Technology, 4, 18-24

Kleinginna Jr., P. R., \& Kleinginna, A. M. (1981). A categorized list of motivation definitions, with a suggestion for a consensual definition. Motivation and Emotion, 5, 263-291.

Le, H. Q. (2020). Factors Affecting Students' Decision to Select Private Universities in Vietnam. Journal of Asian Finance, Economics and Business, 7(4), 235-245. https://doi. org/10.13106/jafeb.2020.vol7.no4.235

Lee, W.-S., \& Kim, B.-Y. (2019). The Effects of Career Orientations on Entrepreneurial Satisfaction and Business Sustainability. Journal of Asian Finance, Economics and Business, 16(4), 235-248. https://doi.org/10.13106/jafeb.2019.vol6.no4.235

Luu, Q. D., Do, A. D., Canh, C. D., Nguyen, T. T. T., \& Thai, T. H. (2019). Applying a multi-criteria decision making to assess lecturer' performance. Journal of Economics and Development, 266, 85-92.

Maslow, A. H. (1943). A Theory of Human Motivation. Psychological Review, 50(4), 370-396. https://doi.org/10.1037/ h0054346

Mertler, H. (1992). Value make the Company. Harvard Business Review, September-October, 81-86.

Nabi, M. N., Islam, M. M., Dip, T. M., \& Hossain, M. A. A (2017). Impact of Motivation on Employee Performances: A Case Study of Karmasangsthan Bank Limited, Bangladesh. Arabian Journal of Business and Management Review, 7(1), 1-8.

Nadeem, M., Ahmad, N., Abdullah, M., \& Hamad, N. (2014). Impact of Employee Motivation on Employee Performance (A Case Study of Private firms: Multan District, Pakistan). International Letters of Social and Humanistic Sciences, 36, 51-58.

Narasuci, W., Setiawan, M., \& Noermijati. (2018). Effect of Work Environment on Lecturer Performance Mediated by Work Motivation and Job Satisfaction. Journal of Applied Management, 16, 645-653.

Negussie, Y. (2014). Motivational factors that affect teachers'work performance in secondary schools of Jijiga city. MA Thesis. Haramaya University, Oromia, Ethiopia.

Njotoprajitno, R. S., Tjahjadi, R. A., Hadianto, B., \& Sunjaya, A. (2020). The Effect of Motivation, Emotional and Spiritual Intelligence on Lecturer Performance. International Journal of Management Science and Business Administration, 6, 40-51.

Rasheed, M. I., Humayon, A. A., Awan, U., \& Ahmed, A. U. D. (2016). Factors affecting teachers' motivation. International Journal of Educational Management, 30, 101-114.

Rasheed, M. I., Sarwar, S., \& Aslam, H. D. (2010). Motivational issues for teachers in higher education: a critical case of IUB. Journal of Management Research, 2, 1-23.

Reeve, J. (2001). Understanding Motivation and Emotion (3rd ed.). New York, NY: Harcourt College Publishers.

Robins, S. P., \& Coulter, M. (2005). Management, International (7th ed). Upper Saddle River, NJ: Pearson Education. 
Schifter, C. C. (2000). Faculty participation in asynchronous learning networks: A case study of motivating and inhibiting factors. Journal of Asynchronous Learning Networks, 4(1), 1522.

Seebaluck, A. K., \& Seegum, T. D. (2013). Motivation among public primary school teachers in Mauritius. International Journal of Educational Management, 27, 446-464.

Shah, M. J., Ur-Rehma, M., Akhtar, G., Zafar, H., \& Riaz, A. (2012). Job Satisfaction and Motivation of Teachers of Public Educational Institutions. International Journal of Business and Social Science, 3(8), 271-281.

Shahzadi, I., Javed, A., Pirzada, S. S., Nasreen, S., \& Khanam, F. (2014). Impact of Employee Motivation on Employee Performance. European Journal of Business and Management, 6, 159-166.

Situma, R. (2015). Motivational factors affecting employees' performance in public secondary schools in Bungoma North
Subcountry, Kenya. International Academic Journal of Human Resource and Business Administration, 1, 140-161.

Tauhed, S. Z., Rasdi, R. M., Ibarahim, R., \& Samah, B. A. (2019). The Influence of Networking, Individual Effort, and Time Management on Research Performance of Academics at Malaysian Research Universities. Revista Publicando, 6(19), 325-338.

Tella, A., Ayeni, C. O., \& Popoola, S. O. (2007). Work Motivation, Job Satisfaction, and Organisational Commitment of Library Personnel in Academic and Research Libraries in Oyo State, Nigeria. Library Philosophy and Practice 2007 (April)

Wright, M. D. (1985). Relationships among esteem, autonomy, job satisfaction and the intention to quit teaching of down-state Illinois industrial education teachers. Doctoral dissertation. Chicago, IL: University of Illinois. 